JELTL (Journal of English Language Teaching and Linguistics) e-ISSN: 2502-6062, p-ISSN: 2503-1848

2019, Vol. 4(2)

www.jeltl.org

\title{
Reflection of Translation Strategies and Translation Norms in the Translation of Persian into English Tourism-related Websites
}

\author{
Sina Shams \\ Master of Translation, Department of Translation, \\ Imam Reza International University, Mashhad Iran \\ Reza Gholami \\ Islamic University of Mashhad, Malayusia \\ e-mail: upmreza@gmail.com
}

\begin{abstract}
The importance of tourism for the economies of the countries is indisputable. In line with this, websites introducing touristy landmarks as well as presenting general information as regards a country play an important role. It is well agreed that translating such websites would be a daunting task and evaluating them is then a need. To fulfil this, the current research was established to address in general the translation of Persian into English tourism-related websites. Toury's Model was adopted to investigate the corpus of the study. The results proved that the most dominant strategy on the tourism related websites was omission, followed by manipulation of segmentation and euphemism. Also it was found that website translators used different strategies in transferring tourism words and sentences. The findings of this research showed that there are deficiencies in terms of norms and strategies. Further professional work is needed to boost the quality of the tourism related websites in the studied areas.
\end{abstract}

Keywords: Toury's Model, Translation Strategies, Translation Norms, Tourism Websites

\section{INTRODCUTION}

Tourism has turned into a significant sector having an influence on development of country economy. Income creation and generation of jobs are the chief merits of tourism. Tourism is the chief source of welfare in numerous countries. The capability of the economy 


\section{Sina Shams \& Reza Gholami}

in the countries to profit from tourism is dependent on the accessibility of investment to expand the needed infrastructure and on its capability to fulfil the tourists' needs (Agaraj \& Murati, 2015). During the last decade, we have been watching the mushrooming and increased use of web devices enabling Internet users to both create and distribute content (multimedia information). The internet content and information generated by users of web technologies are having a enormous effect not only on the profile, expectations and decision making behaviour of Internet users, but also on e-business model that businesses need to expand. The tourism industry is not an exception from such developments. In contrast, as information is the vital spark of the tourism industry the use and flow of Web technologies have a significant impact of both tourism demand and supply. It is of note that in line with this, websites introducing touristy landmarks, accommodations, and related information play a pivotal role in boosting the trourism industry. In line with this, translating such websites to the international audiences matter a great deal.

Nauert (2007, p.1) explains that "Translation is becoming increasingly important in our globalized world as a means of securing communication across languages and cultures. Technological advances and internationalization have contributed to the development of new fast, often short-lived and multilingual forms of internet communication". Vossoughi and Etemad (2013, p.1) claims that "in the process of translation, culture is one of the issues that create many problems for the translator, especially when the source text and the target text belong to different cultures. The problem is even more serious when some concepts exist in both cultures, but have different expressive meanings. Differences in expressive meanings are likely more difficult to handle when the equivalent in the target culture is more emotionally loaded than the source language item. The concept of norm and translation as a norm- governed activity is under- researched in Iran. Because translators are not allowed to transfer every concept or expression into their language and culture, the strategies and the approaches used by translators are very important and critical" (Vossoughi \& Etemad, 2013, p.1).

Munday (2001, p.113) declares that norms are sociocultural constraints that are "specific to a culture, society and time". Individuals attain them from the general process of training and socialization. It is believed by Baker (2001) that norms provide options for translators to choose on an ordered basis. It is believed by Toury (1995) that every community has its own values and the people share these values and ideas. He puts that norms are translation of what is wrong or right. He points that they tell us what is considered adequate or inadequate. Toury (1995, pp.58-59; as cited in Vossoughi \& Etemad, 2013, p.2) introduces three kinds of norms in translation including "initial norms", "preliminary norms" and "operational norms". Initial norms that form the continuum of adequate and acceptable translation. In fact, Toury refers to a general choice the translator makes. If the translator subjects himself to the norms realized in the source culture, adequate translation results; if the target culture norms prevail, translation will be acceptable. He also describes two types of norms: "preliminary" and "operational" (pp. 58-59). The preliminary norms refer to "translation policy and directness of translation" (p. 58). By translation policy, Toury means the factors governing the selection of texts to be translated in a specific language, culture, or 
time: directness of translation relates to whether translation occurs through "an intermediate language" (e.g. Portuguese to Persian via English) (p. 58).

Occasionally the prevailing norms of a society proscribe something to be pointed out, resulting in censorship. Freshwater (2004, p.226) quotes Kuhn (1988) in his study, a researcher who does not consider censorship as "either fixed or monolithic" but as "an ongoing process embodying complex and often contradictory relations of power".

In addition to all the above-mentioned points, the significance of tourism for the economies of a great number of countries is recognized. At the global level, tourism growth rates are increasing, thus contributing to the economic development of many countries. In the face of global competition, it is important for the suppliers of the tourism product and for tourism destinations to realize how consumers behave when choosing a destination for vacation and travel (Lončarić, Bašan, \& Marković, 2013). Fominiene (2016) highlights that in many countries of the world, tourism is considered as one of the most rapidly growing sectors of services, the importance of which is constantly increasing. In fact, Fernando and Long (2012) state that all these features would enable us to make some beliefs that tourism is a widely spread phenomenon and a necessary factor determining economic development while seeking competitive benefits both on regional and on global scales, aiming to maintain, protect and strengthen competitive positions on the global market that has been becoming more and more competitive with every day.

In line with this, the Internet has become a main marketing tool in tourism industry (Buhalis, 2003; Wang, 2008). Tourism organizations are increasingly developing websites to satisfy consumers' needs, and thereby accomplish their business goals (Law, Qi, \& Buhalis, 2010). Though, due to different capacities of an organization to understand and transform the information and communication technology (Yuan, Gretzel, \& Fasenmaier, 2006), not all the organizations are able to efficiently integrate the Internet into their strategic marketing objectives. Website assessment can help organizations track the performance of their websites over a period of time, and thus enable continuous improvements and comparison of site performance against competitors and industry associates (Morrison, Taylor, \& Douglas, 2004). With the increasing change in the technology environment and the consumer taste, it is important that destination organizations evaluate their websites frequently with a standard and valid approach over a certain period of time in order to make sure that the website serves its intended goals (Morrison et al., 2004).

Having considered all the mentioned issues, in the current research, the tourism websites in Iran have been analyzed and studied to see how the norms and thtrategies are applied in line with Toury's model.

\section{LITERATURE REVIEW}

"Translation studies have emerged over the past fifty years as a new interdisciplinary academic field. In the time period between the fifties and seventies, TS formed an integral part of applied linguistics" (Nouraey \& Karimnia, 2012, p.98). As it was mentioned before, "Holmes (1988, as cited by Nouraey \& Karimnia, 2012, p.98) was the first scholar to provide a framework for this discipline by dividing this field of science in two principal areas, translation theory as well as the descriptive science of translation on one hand and the applied TS on the other". 


\section{Sina Shams \& Reza Gholami}

"Although the map was invented in 1972 for the first time, after many years of development in science, it has not lost its validity at all. This comparison is based on today's scholars' ideas" (Nouraey \& Karimnia, 2012, p.98). For instance, where Van LeuvenZwart (1992) groups together theoretical and descriptive TS and differentiates between two broad approaches of the scientific study of translation; theory producing study (p.60).

"Recent key publications on research methods and trends in TS include "Unity in diversity" edited by Bowker, Cronin, Kenny and Pearson (1998), and also "The map" by Williams and Chesterman (2002)" (Nouraey \& Karimnia, 2012, p.98). "While the former publication questions the claim of interdisciplinary characteristics as the essence of TS in view of its theoretical diversity and also disputes the existence of a general theory of translation, the latter one focuses on description of research and research methods in TS. In fact, the latter one lists twelve key areas of translation and suggests possible research directions for each area, roughly corresponding to Holmes' (1988) map of TS" (Nouraey \& Karimnia, 2012, p.98).

"One of the most important issues in the field goes back to the tendency the trend has faced chronologically" (Nouraey \& Karimnia, 2012, p.99). In this regard, to know what scholars believe is in fact of utmost importance. As cited by Nouraey and Karimnia (2012, p.99), Chesterman asserts that "the trend has been towards DTS up to this day, in the general sense that most scholars have stopped assuming that their role is to give advice to translators and propose prescriptive principles. Rather, scholars aim to describe what translators do, what translations are like, and to explain why they are like that" (p.99). "He (ibid.) then continues that in near future more attention will be paid to the translator as an agent, to the people involved in the translation event, not just the texts; more attention to the interface between translators and computers, use of translation memory, use of machine translation as an aid in human translation" (Nouraey \& Karimnia, 2012, p.99).

"Larson believes that the trend has been towards DTS up to this day, too (as cited by Nouraey \& Karimnia, 2012, p.99). In fact, "she (ibid.) points out that in the 1990s most scholars were interested in the practical orientations (i.e. the product and process)" (Nouraey \& Karimnia, 2012, p.99).

As cited by Nouraey and Karimnia (2012), chaeffner believes that "Translation Studies research has expanded enormously. Then there are many issues which are being researched now including not only product and process-oriented ones, but also research into institutional contexts, agency, translation policy, professional aspects, translation industry, technology and many more" (as cited by Nouraey \& Karimnia, 2012, p.99).

As cited by Nouraey and Karimnia (2012, p.99), Munday believes that "there are certainly a lot of product-oriented studies, but recent trends are towards process studies and towards sociological studies of translation. He (ibid.) believes that the global trend is going towards multimodality, machine translation and experimental methodologies. Also, by contrast, more sophisticated cultural and sociological studies are yet to be carried out".

Nouraey and Karimnia (2012) investigated the orientations of M.A students of translation at different universities in Iran. To begin with, one-hundred and twenty theses out of six universities were chosen through the process of cluster sampling. Then, each and every sample was placed in the related branch of Holmes' (1988) map of Translation Studies 
(henceforth TS). At the end, a Chi-square test was carried out in order to see whether there exists a significant difference between the branches and sub-branches of TS chosen by students or not. "The results indicated that there was a statistically significant difference between the frequencies of the twenty-one branches of the map. The results also pointed out that the most frequent branches of TS worked on by Iranian students between 2007 and 2012 were "descriptive" TS with the subbranches of "process-oriented" and "product-oriented" along with "Evaluation of Translations" with the frequency of 48, 44 and 12, respectively" (p.94).

\section{THEORETICAL BACKGROUND: Toury's Norms and Socio-Cultural Constraints (1995)}

"Social life, including language use, is governed by norms-socially shared concepts of appropriate and expected behavior", (Kauhanen, 2010, p.34). Translation is a kind of action which definitely involves at least two languages and two cultural traditions, and hence different conventions and norms (Toury, 2004), so translation activity has cultural significance in societies. Toury (1999, p.14) quoting from Swidler (1986) declares that, the culture affects the action, but such an effect is not in a way that it provides "the ultimate values toward which action is oriented". It shapes a set of habits, skills, and styles for people to construct 'strategies of action'. Therefore, the first and the most important role of translation is a social role and a translator should accomplish such a function in a way that it is supposed to be appropriate in its own reference (Toury, 2004, p.205). Hence "the prerequisite for becoming a translator within a cultural environment" is the acquisition of a set of norms which is suitable for that behavior (p: 205). The socio-cultural dimension of translation can subject it to several constraints (Toury, 1995) and translators should accomplish their tasks under different circumstances. For instance, they translate different kinds of texts for different audiences. Thus, they should adopt different strategies for their translations, and therefore, their products would be different from one another (Toury, 1995).

Norms are the 'key concepts and the focal points' in any activities which are relevant to social life (Toury, 1995, p.200). Norms are considered as 'socio-cultural' constraints (Toury, 2004, p.206). Therefore, they have a prescriptive force for translators, (Chesterman, 1993, p.14). Norms of translation exist at a certain period of time and within a specific society (Schaffner, 1999) and they can be operated in all kinds of translation and all stages of translation, and hence norms will be reflected on every level of its product (Toury, 2004).

These days, in the process of "globalization" and "technological progress", publics can more easily access different texts and translations with different qualities. "Furthermore, in an age which has generated so many new forms of communication", written words on paper should get converted (Chiaro, 2008:241). Movie translation can be demonstrated in the form of dubbing and subtitling. Translation of movies in the form of dubbing plays an important role in every society and can affect the culture of the recipient society in a long period of time (karamitroglou, 2000).

Contemporary studies in the field of translation concentrate to the need to examine the relationship between the production of knowledge in a given culture and its transmission, relocation, and reinterpretation in the target culture, (Álvarez \& Vidal Claramonte, 1996). 


\section{Sina Shams \& Reza Gholami}

As such. the theoretical framework of this study is the one suggested by Toury (1995) on norms in translation. Toury (1995, as cited in Munday, 2001, p.113-115) has introduced three kinds of norms: 'Initial Norms', 'Preliminary Norms', and 'Operational Norms' as described below:

'Initial norms' form the continuum of adequate and acceptable translation which refer to translator's basic decision whether subject him/her to the SL norms to produce adequate TT, or to TL norms to produce acceptable TT (1995, p. 56).

'Preliminary norms' refer to 'translation policy' and 'directness of translation'. By translation policy, Toury refers to factors governing the selection of texts to be translated in a specific language, culture, or time and directness of translation relates to whether translation occurs through an intermediate language (p. 58).

'Operational norms' direct translation decisions during the act of translation (p. 58). 'Matricial norms' and 'text linguistic norms' are subcategories of operational norms. Matricial norms deal with the fullness of translation and the degree to which omission, addition, changes of location and manipulation of the text are done and text linguistic norms govern the selection of TT linguistic material: lexical terms, phrases and stylistic features (pp. 58-59).

\section{RESEARCH METHODS}

\subsection{The Research Design}

This research is qualitative in nature. Qualitative research is a method of inquiry employed in many different academic disciplines, including in the social sciences and natural sciences, but also in non-academic contexts including market research, business, etc. (Denzin \& Lincoln, 2011). Qualitative research is a scientific method of observation to gather non-numerical data.

\subsection{Corpus of the Study}

The research questions of the study seek information about the adequacy or acceptability of the translations in terms of Toury' s norms that lead the study to find the translator's source-oriented or target-oriented approach to the translations. In details, the research tries to determine the extent to which the translator could create adequate and/or acceptable translations according to Toury's translational norms. For this reason, 5 websites of the Cultural Heritage, Handicrafts and Tourism Organization of Iran in different provinces of Iran were selected as shown in Table 1.

Table 1: The main Corpus of the Study

\begin{tabular}{|c|c|c|}
\hline No. & The Selected Organizations & The Website Address \\
\hline 1. & $\begin{array}{l}\text { Cultural Heritage, Handicrafts and Tourism Organization of East } \\
\text { Azarbaijan }\end{array}$ & https://www.eachto.org \\
\hline 2. & $\begin{array}{l}\text { West Azarbaijan Cultural Heritage, Handicrafts and Tourism } \\
\text { administration }\end{array}$ & http://www.urmiachto.ir \\
\hline 3. & Cultural Heritage, Handicrafts and Tourism Organization of Isfahan & http://isfahancht.ir \\
\hline 4. & $\begin{array}{l}\text { Cultural Heritage, Handicrafts and Tourism Organization of Southern } \\
\text { Khorasan }\end{array}$ & http://www.skchto.com \\
\hline 5. & Cultural Heritage, Handicrafts and Tourism Organization of Markazi & https://markazitourist.ir/en/ \\
\hline
\end{tabular}




\subsection{Data Collection Procedure}

Having listed all the available websites, the translations of both the target language and the source language were read thoroughly to find out whether or not the translators have used the strategies and norms and whether such strategies comply with Toury's framework.

\subsection{Data Analysis}

At first, the corpus of this study was compiled as discussed earlier. Then to address the research questions, we took the following steps one by one: to answer the first objective which was to determine the strategies and their frequencies used by the translators in tourism-related website, the strategies based on Toury's model including Euphemism, Omission, and Manipulation of segmentation were identified in the corpus and a list of the common strategies and their frequencies and percentages was prepared for each website and then for all the websites together.

The second objective was to determine whether the translated strategies used by the translators are matched with Toury's translation strategies. Then the norms and strategies used on the basis of Toury's model were identified and listed and reported in the relevant tables.

\section{RESULTS}

\subsection{Results on the Strategies}

In this research, two research questions were established to address the main objective of the study which was to investigate the translation of Persian into English tourism-related websites with a focus on error-based comparative analysis. The first research questions in this study was as follows:

- Research Question One: What are the strategies and their frequencies used by the translators in tourism-related websites?

In classifying the strategies and norms governing translation of the translation of Persian into English tourism-related websites, the research followed Toury's model as described below: "Initial norms" form the continuum of adequate and acceptable translation which refer to translator's basic decision whether subject him/her to the SL norms to produce adequate TT, or to TL norms to produce acceptable TT (Toury, 1995, p. 56). On the other hand, "Preliminary norms" refer to "translation policy" and "directness of translation". By translation policy, Toury refers to factors governing the selection of texts to be translated in a specific language, culture, or time and directness of translation relates to whether translation occurs through an intermediate language (Toury, 1995, p. 58). Finally, "Operational norms" direct translation decisions during the act of translation (Toury, 1995, p. 58). "Matricial norms" and "text linguistic norms" are subcategories of the operational norms. The latter deals with the fullness of translation and the degree to which omission, addition, changes of location and manipulation of the text are done and former governs the selection of TT linguistic material: lexical terms, phrases and stylistic features (Toury, 1995, p. 58-59).

The selected websites presented in the study corpus have been analyzed to seek the norms, that is, the preliminary, initial and operational decisions of the translator, and the strategies with which the norms are associated. Therefore, translational norms of Toury have 


\section{Sina Shams \& Reza Gholami}

been used to make detailed analyses of the equivalence of translation, punctuation and sentence and paragraph structure. More importantly, the selected websites have also been analyzed to find the tendency of translators to create 'adequate' and 'acceptable' translations that leads the analysis to find the translator's source-oriented or target-oriented approach to the translations.

Toury suggests that translation naturally has equivalence but the focus point should be the 'type and extent' of this equivalence. He states that norms are the determiner of the equivalence and they are the internalized, regular behaviour and decisions of translator. So, Toury takes translation as a norm-governed activity. He describes three different kinds of norms, mainly, initial norms, preliminary norms and operational norms and all these norms operate at different stages of the translation process.

The findings of the study are presented in the light of research questions and they are given based on the websites being collected and compiled as the study corpus, a tourismrelated corpus of the Iranian websites of tourism. As it has been mentioned before, it is only possible to mention the adequacy or acceptability of the translation, when the preliminary norms and operational norms are described in detail. So, the first question intends to describe and analyse all these strategies that govern the translations.

In this sense, when the websites were analyzed in line with Toury's preliminary norms, it is possible to suggest about the directness of the translations and also about the translation policy of the Cultural Heritage, Handicrafts and Tourism Organization in Iran and the translator. As the websites claim, the target audience of the translated websites is the people travelling to Iran from different countries; for this reason, the direction of the translation is from Persian to English. The translators have been recruited to translate the tourist attractions directly from the SL (Persian language) to the TL (English language) without any mediating language.

As for the strategies being used, all the gathered data were categorized systematically, and following some other studies such as (Sedighi \& Najian, 2012; Vossoughi \& Etemad, 2013), three main strategies based on Toury's model were detected and identified in all the texts related to the 5 study websites. These strategies included Euphemism, omission, and manipulation of segmentation which are described earlier.

Euphemistic words or expressions help us to talk about unpleasant things and 'neutralize' them, (Wardhaugh, 1990, p. 231). Euphemistic things also allow us "to give labels to unpleasant tasks and jobs in an attempt to make them sound almost attractive" (Wardhaugh, 1990, p. 231). In other words, euphemism is "the glorification of the commonplace and elevation of the trivial" (Wardhaugh, 1990, p. 231).

Regarding the omission, Toury $(1995$, p. 82 ) has successfully shown that omission is a legitimate translation strategy, and it is perhaps used in literary translation than in any other form of translation, due to the restrictions imposed by culture". According to Ivacovoni, (2009, p. 101) "Omission means dropping a word or words from the SLT while translating. This procedure can be the outcome of the cultural clashes that exist between the SL and the TL. In fact, it is in literary texts translations where omission attains its peak in use. The translator omits words that do not have equivalents in the TT, or that may raise the hostility of the receptor". Baker (1992, pp. 26-42) also identifies translation by omission saying that 
this may be a drastic kind of strategy, but in fact it may be even useful to omit translating a word or expression in some contexts. If the meaning conveyed by a particular item or expression is not necessary to mention in the understanding of the translation, translators use this strategy to avoid lengthy explanations. Moreover, Safaei and Vahid Dastjerdi (2017) consider Zero translation (total omission or deletion of the device) as one strategy to be used.

Regarding the manipulation of segmentation i.e. large scale omissions, restructuring of a text, Gambier and Van Doorslaer (2010) highlight that the so-called matricial norms may govern the very existence of target-language material intended as a substitute for the corresponding source-language material (and hence the degree of fullness of translation), its location in the text (or the form of actual distribution), as well as the textual segmentation. The extent to which omissions, additions, changes of location and manipulations of segmentation are referred to in the translated texts (or around them) may also be determined by norms, even though the one can very well occur without the other. Venuti (2012) claims that large-scale omissions often entail changes of segmentation as well, especially if the omitted portions have no clear boundaries, or textual-linguistic standing, i.e., if they are not integral sentences, paragraphs or chapters.

The results and findings of the analyses related to the abovementioned strategies being used by the translators of the tourism related websites being considered as the corpus of this research have been reported in Tables 2-6. Regarding the first website, which was for the Cultural Heritage, Handicrafts and Tourism Organization of East Azarbaijan Province, it was observed that although there are both Persian and English versions, the two have considerable differences. While on the Persian website for Tabriz, as the center of the province, information such as history and background, geographical location, climate, cultural characteristics, as well as historical and going places have been described in separate sections, the English version presents some other sections which differ such as history, early accounts, from the Muslim conquest to Qajars, contemporary age, and capital of Iran. In the only section for history and background, yet, on both versions, different sentences are presented i.e. the ones on the English version are not totally equivalent with the ones no the source language. However, some sentences were detected to be equivalent and the strategies used to translate them were identified.

As it is shown in Table 2, which are about the used strategies, their frequencies, and percentages about East Azarbaijan Province, the most frequent strategy was found to be Omission with $83.33 \%$, followed by $16.66 \%$ while euphemism was never used. On this website, many Persian sentences were omitted while some extra information had been presented for the foreigners.

Table 2: The used strategies, their frequencies, and percentages in the corpus of East Azarbaijan Province

\begin{tabular}{llll}
\hline No. & Strategy & Frequencies & Percentage \\
\hline 1 & Euphemism & 0 & $0 \%$ \\
\hline 2 & Omission & 45 & $83.33 \%$ \\
\hline 3 & Manipulation of segmentation & 9 & $16.66 \%$ \\
\hline Total & & 54 & $100 \%$
\end{tabular}

JELTL (Journal of English Language Teaching and Linguistics), 4(2), 2019 
As regards manipulation of segmentation and omission, the following sentence could be exemplified. Although in the Persian version some other phrases have been reported, the English version totally changes this sentence. For example, the clause "دار ای باروى تودرنو is totally omitted in the English Version:

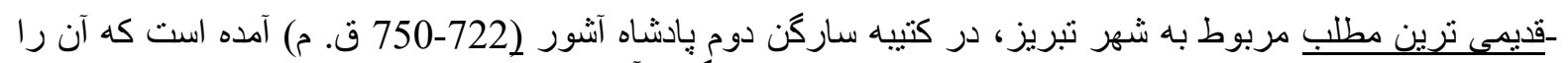

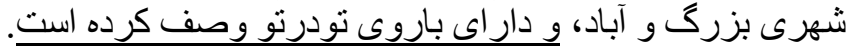

- For the first time, Tarui or Tauris or Medes of are mentioned in Assyrian King Sargon II's epigraph in 714 B.C.

There were many other instances of omission and manipulation of segmentation in this corpus and the reason for these additions or omissions are discussed in the next section, which is the discussion of the findings.

The subsequent section deals with the strategies being used on the website of the Cultural Heritage, Handicrafts and Tourism Organization of West Azarbaijan Province. As shown in Table 3, totally a sum of 57 strategies were used and the largest amount belonged to omission with 30 strategies $(52.63 \%)$ while manipulation of segmentation comes next with 26 strategies $(45.61 \%)$. The least was euphemism with only 1 strategy constituting $1.75 \%$ of the whole strategies.

Table 3: The used strategies, their frequencies, and percentages in the corpus of West Azarbaijan Province

\begin{tabular}{llll}
\hline No. & Strategy & Frequencies & Percentage \\
\hline 1 & Euphemism & 1 & $1.75 \%$ \\
\hline 2 & Omission & 30 & $52.63 \%$ \\
\hline 3 & Manipulation of segmentation & 26 & $45.61 \%$ \\
\hline Total & & 57 & $100 \%$ \\
\hline
\end{tabular}

The only instance of euphemism in this corpus for West Azarbaijan was translating the word "كليساى نه نه مريح" into "Church of Saint Mary". As for the omission and manipulation of segmentation which were the highest used strategies, many examples could be identified, two of which are given below:

-ـيل بار اندوز در روستاى بار اندوز شهرستان اروميه و اقع شده و قدمت آن به دوره قاجار ميرسد. اين يُّ تاريخى داراى

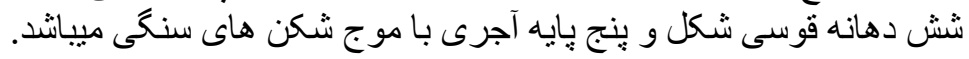

- The bridge is located 25 kilometers road urmia oshnavieh and has been constructed on the river Barandouz. 


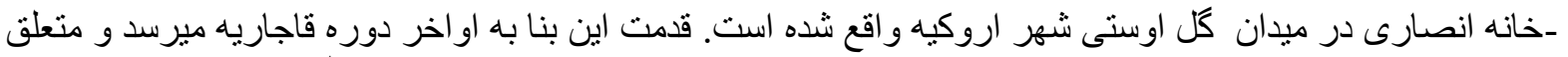

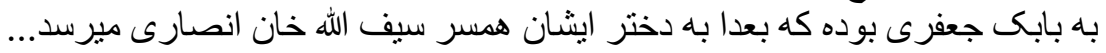

- Building belongs to the Babak Jafari and then to his daughter, who is the wife of Saifullah Khan Ansari reached. The antiquity is related to The Pahlavi era.

Along these reported strategies, there were many additions on the English version while they were totally omitted or missing in the original Persian version. The reason for such policies will be discussed later along with the existing errors in the subsequent sections.

The following section deals with the strategies being used on the website of the Cultural Heritage, Handicrafts and Tourism Organization of Isfahan Province. It needs to be asserted that this was the longest corpus in comparison with the corpus of the other selected provinces. As shown in Table 4, totally 295 strategies had been used by the translator and the largest belonged to omission with a frequency of 232 strategies constituting $78.64 \%$ of all the used strategies. Manipulation of segmentation ranked second with 63 frequencies and a percentage of $21.35 \%$. Euphemism was never used by the translator on the Isfahan website.

Table 4: The used strategies, their frequencies, and percentages in the corpus of Isfahan Province

\begin{tabular}{llll}
\hline No. & Strategy & Frequencies & Percentage \\
\hline 1 & Euphemism & 0 & $0 \%$ \\
\hline 2 & Omission & 232 & $78.64 \%$ \\
\hline 3 & Manipulation of segmentation & 63 & $21.35 \%$ \\
\hline Total & & 295 & $100 \%$ \\
\hline
\end{tabular}

Some examples of omission and manipulation of segmentation are given below:

ـاين مسجد يكى از زيباترين بناهاى جهان اسلام است كه در ضلع جنوبى ميدان نقش جهان و اقع شده است

- On the southern side of the square stands the magnificent portal of the Abbasi Jame Mosque with its twin flanking minarets.

$$
\text { -درى كه به شبستان اصلى ر اهد دارد تاريخ } 953 \text { ه.ق را بر روى خود دارد. }
$$

- The door is made of walnut and dates back to 1545 . -اين مسجد كه متعلق به عصر ايلخانيان است در محله معروف يرز لله قرار دارد.

- The Porzaleh Mosque is located in the main street of Abiyaneh.

The fact is that on the website of Isfahan, there are so many extra sentences explaining the historical places for the foreigners in the English version while the Persian one gives some more different information. It seems some policies have been regarded by the translators to do so, which will be discussed later in this chapter.

As for the strategies used on the website of Cultural Heritage, Handicrafts and Tourism Organization of Markazi Province, it is observed in Table 5 that the most frequent strategy was omission, followed by manipulation while the least frequent was euphemism. It is 


\section{Sina Shams \& Reza Gholami}

indeed, observed that $50 \%$ of the strategies were omission while manipulation was $40 \%$ and the least was euphemism for only $10 \%$.

Table 5: The used strategies, their frequencies, and percentages in the corpus of Markazi Province

\begin{tabular}{llll}
\hline No. & Strategy & Frequencies & Percentage \\
\hline 1 & Euphemism & 1 & $10 \%$ \\
\hline 2 & Omission & 5 & $50 \%$ \\
\hline 3 & Manipulation of segmentation & 4 & $40 \%$ \\
\hline Total & & 10 & $100 \%$ \\
\hline
\end{tabular}

As for the omission, it was found, for example, that although in the Persian version, the text reported the building belonged to Ghajari Era, in the English version, and it was omitted.

-اين قلعه در شهر خمين و مربوط به دوره قاجار است

- Sālār Mohtashm Fortress and Ethnology Museum is located northeast of Khomein in its old, traditional quarter.

The example for euphemism is as follows, where the translator tried to change the word " into "pavilion" to make it more sensible or better, as the Persian one may connote a negative meaning in the English version for the tourists.

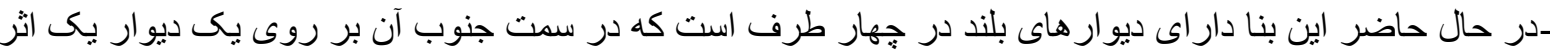

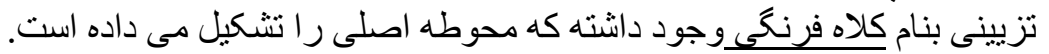

- Sālār Mohtashm fortress has four high walls around it with a pavilion in south one.

Regarding manipulation of segmentation, the following sentence could be exemplified. Although in the Persian version some other phrases have been reported, the English version totally changes this sentence.

ـساختمان اصلي شامل جند اتاق تو در تو است كه فضاى داخلى توسط رف ها و مجسمه هايي كه نشان از فرهنى منطقه ندارد تزبين شده است.

- The main part of the building is interconnected rooms with shelves decorated with western-style statues.

However, it needs to be asserted that there were many additions in the English version to provide some more information about the translated building. The reason why so many sentences existed in the English version but missing in the original Persian one, i.e. the latter was rather lengthy while the former was a bit short would be unclear but it might be related 
to the translation policy to provide further information for the foreign tourists to probably make it a more attractive place to visit.

Considering the strategies being used on the website of the Cultural Heritage, Handicrafts and Tourism Organization of Southern Khorasan Province, it is observed in Table 6 that the most frequent strategy was Manipulation of segmentation, followed by omission while no euphemism was detected. As a matter of fact, it is observed that $93.33 \%$ of the strategies were Manipulation of segmentation while only $6.66 \%$ of the strategies were omission.

Table 6: The used strategies, their frequencies, and percentages in the corpus of Southern Khorasan Province

\begin{tabular}{llll}
\hline No. & Strategy & Frequencies & Percentage \\
\hline 1 & Euphemism & 0 & 0 \\
\hline 2 & Omission & 1 & $6.66 \%$ \\
\hline 3 & Manipulation of segmentation & 14 & $93.33 \%$ \\
\hline Total & & 15 & $100 \%$ \\
\hline
\end{tabular}

As for the omission, it was found, for example, that although in the Persian version, the text reported one piece of extra information, in the English version, it was omitted.

-دق اكبرآباد در شمال غربى كوير لوت و اقع شده و منطقه اى است وسيع از خاكهاى سله بسته كه به دق اكبر آباد

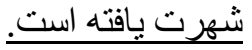

- The Dagh-e Akbar Abad is located Northwest of the Lout Desert.

Regarding manipulation of segmentation, the following sentence could be exemplified. Although in the Persian version some other phrases have been reported, the English version totally changes these sentences and the meaning is sometimes hampered. The translator mistakenly translated "ييمايش كوير به صورت يياده روى" as "walking to survey the desert".

ـكوير بشرويه در فاصله 20 كيلو مترى شمال شرق بشرويه قرار داشته و مناسب جهت بيمايش كوير به صورت يياده روى بودهد.

- The Boshruyeh Desert is located at a distance of $20 \mathrm{~km}$ North East of Boshruyeh and walking to survey the desert.

The most noticeable point about this website is that the translator has repeatedly and frequently presented errors and grammatical mistakes that could easily hamper the meaning for the foreigners and this feature is discussed in the following sections. Nonetheless, the translator was much more loyal to the Persian version and translated almost everything, as contrasted to the translator for the website of Markazi Province discussed earlier. 


\section{Sina Shams \& Reza Gholami}

The following sections elaborate on sum of all the strategies used by translators of all the websites as well as the most frequent strategies being used on each website, in addition to discussing the sum of the strategies being employed by the translators of the selected websites.

According to Table 7, except for euphemism not being used on three websites, the other two strategies were frequently used by the translators. Considering euphemism, it is found that the largest amount belongs to Markazi Province with $10 \%$, followed by West Azarbaijan with a percentage of $1.75 \%$, while for the rest of the provinces it was zero. As for omission, the translator on East Azarbaijan website used it more than the others with a percentage of $83.33 \%$; the least belonged to Southern Khorasan, though. Concerning the manipulation of segmentation, Southern Khorasan comes first with the percentage of $93.33 \%$ while East Azarbaijan comes last (16.66\%). Further details have been depicted in Figure 1.

Table 7: The most frequent strategy on each website

\begin{tabular}{llllll}
\hline \multicolumn{5}{c}{ Percentage } \\
\hline Strategy & E.Azarbaijan & W.Azarbaijan & Isfahan & Markazi & S. Khorasan \\
\hline Euphemism & $0 \%$ & $1.75 \%$ & $0 \%$ & $10 \%$ & $0 \%$ \\
\hline Omission & $83.33 \%$ & $52.63 \%$ & $78.64 \%$ & $50 \%$ & $6.66 \%$ \\
\hline $\begin{array}{l}\text { Manipulation } \\
\text { of } \\
\text { segmentation }\end{array}$ & $16.66 \%$ & $45.61 \%$ & $21.35 \%$ & $40 \%$ & $93.33 \%$ \\
\hline & $100 \%$ & $100 \%$ & & & \\
\hline
\end{tabular}

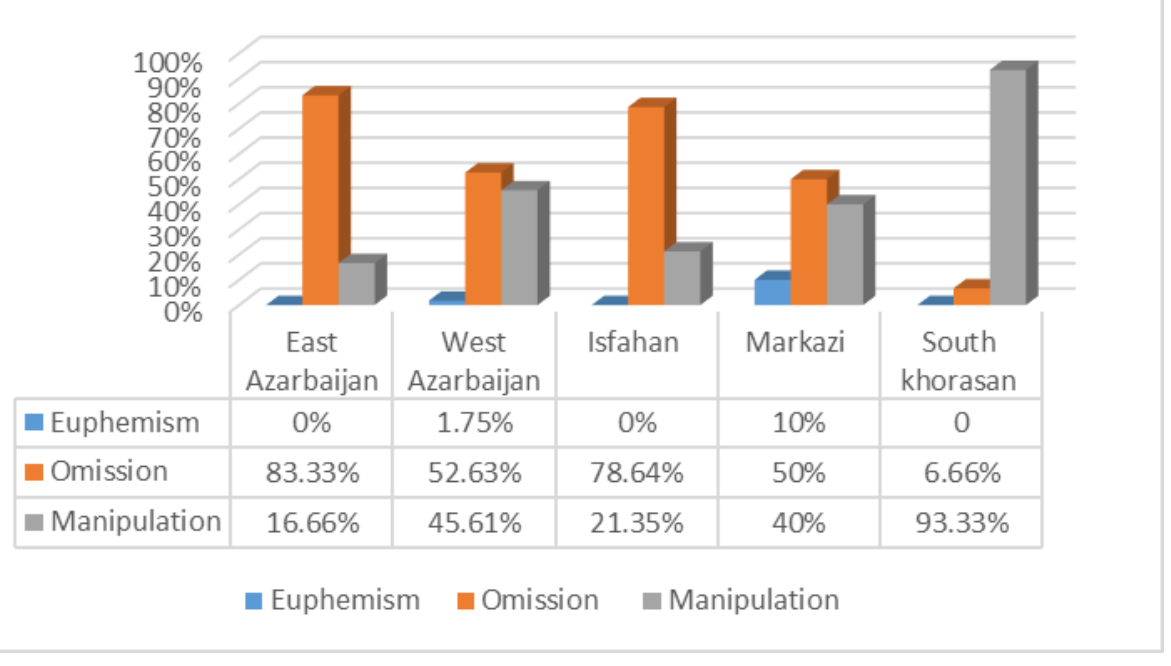

Figure 1: The strategies on each website 
Table 8 shows the most dominant strategy in each tourism-related website being studied in our research. The frequency and percentage of the most dominant strategy has been measured for every website, independently. In Figure 2, all the used strategies for tourism-related words and sentences on each website have been shown as well. As it is observed, except for one website, i.e. Southern Khorasan, where the most frequent strategy was manipulation of segmentation with a frequency of 14 and a percentage of $93.33 \%$, on the rest of the websites the most frequent strategy being dominantly used by the translators was omission. For instance, for East Azarbaijan, the frequency was 45 with a percentage of 83.33\%. For West Azarbaijan, the frequency was 30 with a percentage of $52.63 \%$. Moreover, for Isfahan, the frequency was 232 with a percentage of $78.64 \%$. For Markazi, the frequency was 5 with a percentage of $50 \%$.

Nonetheless, it is found that the biggest frequency of omission in terms of percentage belongs to East Azarbaijan followed by Isfahan, meaning that in these corpuses, the translators used omissions, not only more than the other two strategies but also used omissions more than the other translators in their renderings. Figure 2 presents further details about the obtained findings in this section, i.e. the most frequent strategies used on each website.

Table 8: The most frequent strategy on each website

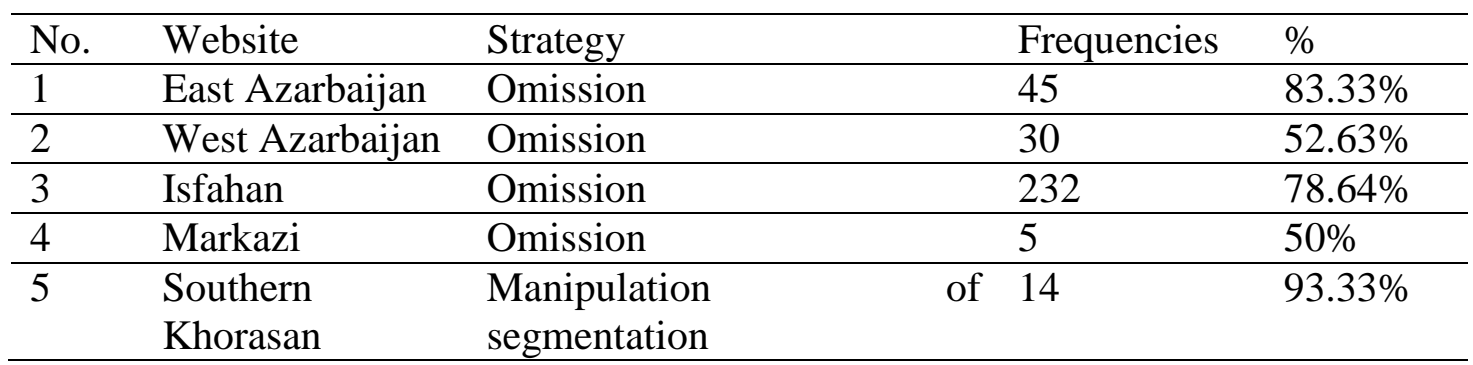

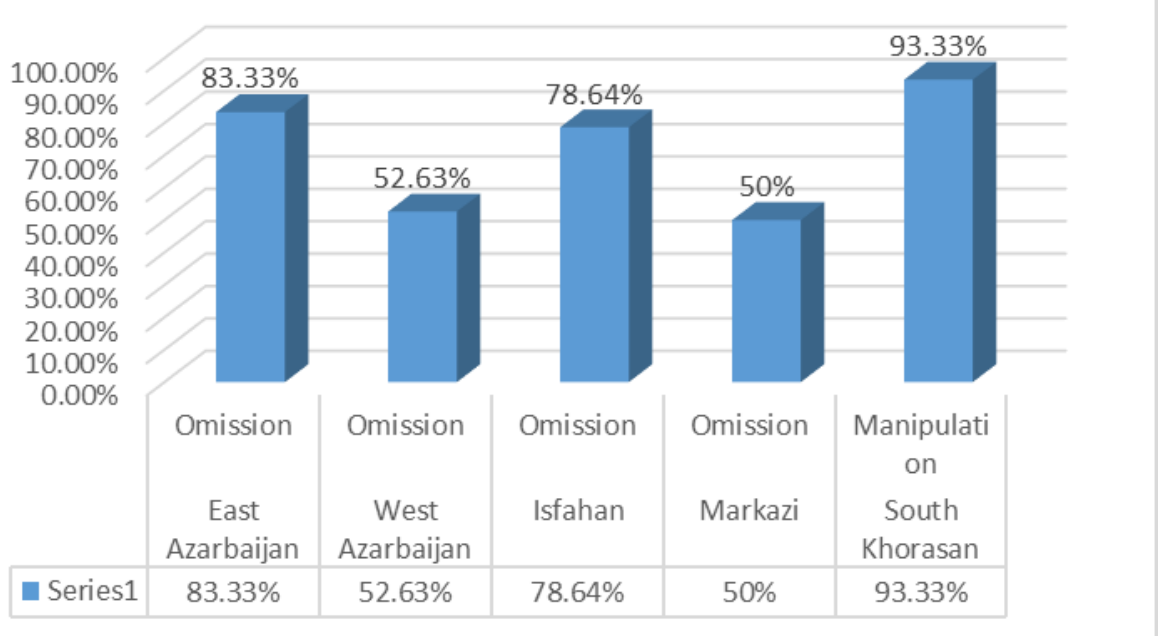

Figure 2: The most frequent strategy on each website

JELTL (Journal of English Language Teaching and Linguistics), 4(2), 2019 


\section{Sina Shams \& Reza Gholami}

Table 9 illustrates the total sum of the most frequent strategies and the related percentage among all the selected websites. As the distribution of strategies shows, totally, 431 strategies including Euphemism, Omission, and Manipulation of segmentation had been used by the translators of the selected tourism related websites. Out of 431 instances of the collected data, 2 instances $(0.46 \%)$ belonged to the strategy of euphemism being employed very rarely and remaining as the least used strategy. However, omission was found to be the most frequent strategy with an occurrence of 313 times and a percentage of $72.62 \%$. In fact, around three quarters of the strategies were found to be omission. The next category of frequency belonged to manipulation of segmentation which had a frequency of 116 with a percentage of $26.91 \%$, just above a quarter of the while strategies being used. In general, omission was the most frequent strategy being employed by the translators of the tourism related websites being studied in this research. It is of note that further discussion and the reasons for such strategy use come later in this chapter in the discussion section. The subsequent section also elaborates on the second research question formulated in this study concerning the norms being sued by the translators in harmony with Toury's model.

Table 9: The frequency and percentage of the used strategy on all websites

\begin{tabular}{llll}
\hline No. & Strategy & Frequencies & Percentage \\
\hline 1 & Euphemism & 2 & $0.46 \%$ \\
\hline 2 & Omission & 313 & $72.62 \%$ \\
\hline 3 & Manipulation of segmentation & 116 & $26.91 \%$ \\
\hline Total & & 431 & $100 \%$ \\
\hline
\end{tabular}

After discussing the frequency and type of the used strategy on all websites, the next section elaborates on the second research question which investigates whether strategies comply with Toury's model of norms and strategies.

\subsection{Results on Norms}

In line with the first research question which investigated the strategies and their frequencies used by the translators of tourism related websites in Iran, the second research question goes deeper to find out whether the used strategies comply with Toury's model of norms and strategies. In details the second research question is as follows:

- Research Question Two: Are the translated strategies used matched with Toury's translation strategies?

To contrast each ST-TT pair of the study corpus, which encompassed the tourism related websites in Iran, and to investigate the strategies used in tourism related websites' words and sentences, many examples were collected from the Persian websites compiled as a corpus and were compared with their English versions. In order to categorize the data, the 
first step was to organize them in a systematic form i.e., those data containing tourism related information with their English versions were gathered. The unit of analysis ranged from one word, a phrase, to a sentence which contained tourism related concepts to several sentences. It should be noted that continuous truism related words and sentences were considered as one example.

In the next step, the extracted examples were organized in PDF files, and the type of the strategy used was inserted in front of each example. Three strategies were used for truism related words within the truism related websites in Iran, including euphemism, omission, and manipulation of segmentation. Table 10 exhibits some examples which were selected randomly. Toury's (1995) translation norms were used for data analysis. As explained before, Toury introduces three types of norms: 'Initial norm', 'Preliminary norms', and 'Operational Norms'. For this study, there is no intermediate language and the translation occurs directly from English into Persian.

At the first stage, Toury (1995) divides operational norms into 'matricial norms' and 'text linguistic norms'. Metrical norms related to the completeness of the TI and the strategies used are omission or relocation, addition, and manipulation of segmentation, etc. Manipulation of segmentation occurs when there is a large scale of manipulation, such as omission of several consequence sentences or changing the name of the work. Textuallinguistic norms also govern the selection of linguistic material of the TT, such as lexical items, phrase, and stylistic features. In summary, all the related norms being used by the translators in this study are listed in table 10 based on some randomly selected examples.

Table 10. Norms and strategies used on the basis of Toury's model

\begin{tabular}{|c|c|c|c|c|}
\hline No. & Persian Instances & $\begin{array}{l}\text { English } \\
\text { Translation }\end{array}$ & Strategies & Norms \\
\hline 1 & كليساى نه نه مريم & $\begin{array}{l}\text { Church of } \\
\text { Saint Mary }\end{array}$ & Euphemism & $\begin{array}{l}\text { Operational norms: textual- } \\
\text { linguistic } \\
\text { Initial Norms: acceptable } \\
\text { translation }\end{array}$ \\
\hline 2 & كلاه فرنكى & pavilion & Euphemism & $\begin{array}{l}\text { Operational norms: textual- } \\
\text { linguistic } \\
\text { Initial Norms: acceptable } \\
\text { translation }\end{array}$ \\
\hline 3 & دار اى باروى تودرتو & -------- & Omission & $\begin{array}{l}\text { Operational norms: matrical } \\
\text { Initial Norms: acceptable } \\
\text { translation }\end{array}$ \\
\hline 4 & اين قلعه در شهر خمين و مربوط به دورار است & -------- & Omission & $\begin{array}{l}\text { Operational norms: matrical } \\
\text { Initial Norms: acceptable } \\
\text { translation }\end{array}$ \\
\hline 5 & وله منطقه اى است به وسيع آز خاكهاد شهرت & -------- & Omission & $\begin{array}{l}\text { Operational norms: matrical } \\
\text { Initial Norms: acceptable } \\
\text { translation }\end{array}$ \\
\hline 6 & درى كه به شبستان اصلى راه & -------- & Manipulation & Operational norms: matrical \\
\hline
\end{tabular}

JELTL (Journal of English Language Teaching and Linguistics), 4(2), 2019 
Sina Shams \& Reza Gholami

\begin{tabular}{|c|c|c|c|}
\hline & لدارد تاريخ 953 ه.ق رود دارد. & & $\begin{array}{l}\text { Initial Norms: acceptable } \\
\text { translation }\end{array}$ \\
\hline 7 & 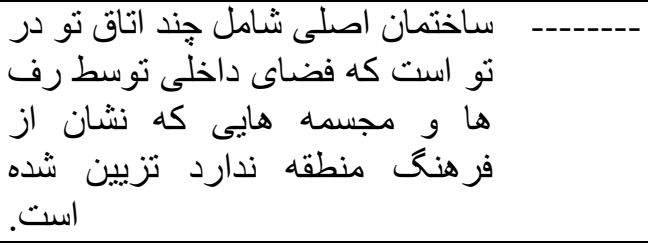 & Manipulation & $\begin{array}{l}\text { Operational norms: matrical } \\
\text { Initial Norms: acceptable } \\
\text { translation }\end{array}$ \\
\hline 8 & 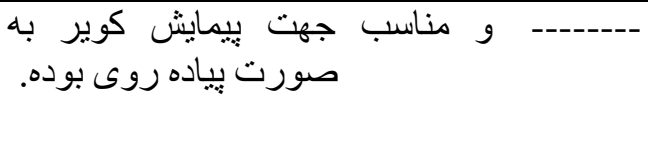 & Manipulation & $\begin{array}{l}\text { Operational norms: matrical } \\
\text { Initial Norms: acceptable } \\
\text { translation }\end{array}$ \\
\hline
\end{tabular}

As the summary of the above statistical figures and tables shows, it can be concluded that, based on Toury's (1995) 'operational norms' and the strategies which can govern this kind of norms, three strategies of euphemism, omission, and manipulation of segmentation have been used for tourism related words and sentences from Persian into English on tourism related websites in Iran. The strategy of euphemism with the percentage of $0.46 \%$ was the least frequent strategy among the used ones, i.e. euphemism was the least frequent strategy in this research. Yet, the most frequent strategy was omission with $72.62 \%$, and the second frequent strategy was manipulation of segmentation with the percentage of $26.91 \%$. None of tourism related instances in the investigated data have been translated without any change or manipulation. In other words, all of the collected data have undergone the strategies of euphemism, omission, and manipulation of segmentation.

Among the five selected websites, Isfahan had the highest number of euphemism, omission (or censorship), and manipulation of segmentation strategies with a frequency of 295, followed by West Azarbaijan with a number of 57 strategies.

To determine the dominant norm among the used strategies in transferring tourism related words from Persian into English on tourist related websites, it is referred to Catford (1965) who believes that the frequency of a shift in translation which is more than $30 \%$ can be considered a norm. Therefore, it can be concluded that in this research, omission with the frequency of higher than $30 \%$ is considered a norm in translating tourism related words and concepts.

As above tables and figures show, all of the collected data which contain tourism related words and sentences were subjected to changes in order to match the values and the beliefs of the target culture. It can also be concluded that in translating the tourism related words from Persian into English, the translators try to produce 'acceptable' translation, i.e. based on Toury's 'initial norm' and translators' decision in subjecting themselves to the norms of source language or target language in order to produce 'adequate' or 'acceptable' translation. The above findings show that, the translators of the tourism related websites employ different strategies (such as euphemism, omission, and manipulation of segmentation to subject themselves to the values and beliefs of the target language and shift from source language to produce 'acceptable' translation.

The findings along with tables and figures can provide suitable guidelines to the translators of the tourism related websites to transfer tourism related words from Persian into 
English. The results of this study introduced the most frequent strategies and a dominant norm in translating tourism related words from Persian into English. Since the most frequent strategy was omission, this strategy can be taken into account in learning and teaching how to translate tourism related words from Persian into English. No need to say that, teachers and students in translation can rely on the findings of this study in translation classes.

Three types of norms in Toury's model which are 'initial norms', 'preliminary norms' and 'operational norms', were at work in this research. Regarding initial norms and according to the findings and data analysis, it should be mentioned that in all the selected websites, all the translators tried to produce acceptable translation, i.e. the translators tended to subject themselves to the norms of target language and produce acceptable translation. Indeed, website translators used different strategies in transferring tourism words and sentences in order to meet the cultural, moral, and religious values as well as the expectations of the societies.

\section{DISCUSSION}

The first research question established in this research was to identify the strategies and their frequencies used by the translators in tourism-related websites. Based on Toury's model, three norms including initial norms, preliminary norms, and operational norms were identified in the corpus of this study. When the websites were analyzed in line with Toury's preliminary norms, it is possible to suggest about the directness of the translations and also about the translation policy of the Cultural Heritage, Handicrafts and Tourism Organization in Iran and the translator. As the websites claim, the target audience of the translated websites is the people travelling to Iran from different countries; indeed, the direction of the translation is from Persian to English. The translators have been recruited to translate the tourist attractions directly from the SL (Persian language) to the TL (English language) without any mediating language. Regarding the strategies, three main categories were detected and identified based on Toury's model in all the texts related to the study corpus. These strategies included Euphemism, omission, and manipulation of segmentation. In further details, the most dominant strategy, out of these, was omission in almost all websites, except for one website. The instances of omission constitute $72.62 \%$ of all the strategies being used. The next is manipulation of segmentation $26.91 \%$ whereas euphemism was the least frequent $0.46 \%$.

Regarding the second research question, which was to determine whether the translated strategies used matched with Toury's translation strategies or not, many examples were collected from the Persian websites compiled as a corpus and were compared with their English versions to contrast each ST-TT pair of the study corpus, which encompassed the tourism related websites in Iran, and to investigate the strategies used in tourism related websites' words and sentences. Three strategies were used for truism related words within the truism related websites in Iran, including euphemism, omission, and manipulation of segmentation. Toury's (1995) translation norms were used for data analysis including 'Initial norm', 'Preliminary norms', and 'Operational Norms'. The initial norm looks for adequate and acceptable translation. 'Preliminary norms' govern 'translation policy' and 'directness of translation'. 'Translation policy' refers to the factors which determine the selection of text for translation in specific culture, language or time. 'Directness of translation' relates to an 


\section{Sina Shams \& Reza Gholami}

intermediate language which a translation occurs. For this study, there is no intermediate language and the translation occurs directly from English into Persian. At the first stage, Toury divides operational norms into 'matricial norms' and 'text linguistic norms'. Metrical norms related to the completeness of the TI and the strategies used are omission or relocation, addition, and manipulation of segmentation, etc. Manipulation of segmentation occurs when there is a large scale of manipulation, such as omission of several consequence sentences or changing the name of the work. Textual-linguistic norms also govern the selection of linguistic material of the TT, such as lexical items, phrase, and stylistic features. Considering all the examined examples and samples, it can be concluded that, based on Toury's (1995) 'operational norms' and the strategies which can govern this kind of norms, three strategies of euphemism, omission, and manipulation of segmentation have been used for tourism related words and sentences from Persian into English on tourism related websites in Iran. The strategy of euphemism was the least frequent strategy while the most frequent strategy was omission and the second frequent strategy was manipulation of segmentation. None of tourism related instances in the investigated data have been translated without any change or manipulation. In other words, all of the collected data have undergone the strategies of euphemism, omission, and manipulation of segmentation.

To determine the dominant norm among the used strategies in transferring tourism related words from Persian into English on tourist related websites, it is referred to Catford (1965) who believes that the frequency of a shift in translation which is more than $30 \%$ can be considered a norm. Therefore, it can be concluded that in this research, omission with the frequency of higher than $30 \%$ is considered a norm in translating tourism related words and concepts. Moreover, all of the collected data which contain tourism related words and sentences were subjected to changes in order to match the values and the beliefs of the target culture. It can also be concluded that in translating the tourism related words from Persian into English, the translators try to produce 'acceptable' translation, i.e. based on Toury's 'initial norm' and translators' decision in subjecting themselves to the norms of source language or target language in order to produce 'adequate' or 'acceptable' translation. The above findings show that, the translators of the tourism related websites employ different strategies (such as euphemism, omission, and manipulation of segmentation) to subject themselves to the values and beliefs of the target language and shift from source language to produce 'acceptable' translation. Since the most frequent strategy was omission, this strategy can be taken into account in learning and teaching how to translate tourism related words from Persian into English. Three types of norms in Toury's model which are 'initial norms', 'preliminary norms' and 'operational norms', were at work in this research. Indeed, website translators used different strategies in transferring tourism words and sentences in order to meet the cultural, moral, and religious values as well as the expectations of the societies.

\section{CONCLUSIONS}

The most dominant strategy on the tourism related websites was omission, constituting $72.62 \%$ of all the strategies. The next strategy was manipulation of segmentation with a rate of $26.91 \%$. Finally, euphemism was found to be the least frequent strategy of all; $0.46 \%$. 
As for compliance of the strategies with Toury's model, it was found that three types of norms in Toury's model which are 'initial norms', 'preliminary norms' and 'operational norms', were at work in this research. Indeed, website translators used different strategies in transferring tourism words and sentences in order to meet the cultural, moral, and religious values as well as the expectations of the societies. In terms of Directness of translation, for this study, there was no intermediate language and the translation occurs directly from English into Persian.

It can be concluded that, based on Toury's (1995) 'operational norms' and the strategies which can govern this kind of norms, three strategies of euphemism, omission, and manipulation of segmentation have been used for tourism related words and sentences from Persian into English on tourism related websites in Iran.

The frequency of the strategies was as follows: (1) omission as the most frequent strategy, (2) manipulation of segmentation as the second frequent strategy and (3) euphemism as the least frequent strategy. None of tourism related instances in the investigated data have been translated without any change or manipulation. In other words, all of the collected data have undergone the strategies of euphemism, omission, and manipulation of segmentation. Moreover, it can be concluded that in this research, omission with the frequency of higher than $30 \%$ is considered a norm in translating tourism related words and concepts.

In translating the tourism related words from Persian into English, the translators tried to produce 'acceptable' translation, i.e. based on Toury's 'initial norm' and translators' decision in subjecting themselves to the norms of source language or target language in order to produce 'adequate' or 'acceptable' translation.

\section{REFERENCES}

Agaraj, X., \& Murati, M. (2015). Tourism an important sector of economy development. Analele Universităţii Constantin Brâncuşi din Târgu Jiu: Seria Economie, 1(1), 83-90.

Al-Badi, A., \& Naqvi, S. (2009). A Conceptual Framework for Designing Localization Business Websites. Journal of Management and Marketing Research , 113-120.

Alvarez, R. \& M. Carmen-Africa V. (1996). Translating: A political act. In: R. Alvarez \& M. Carmen-Africa Vidal (Eds.), Translation, power, supervision (pp. 1-9). Clevedon/ aPhiladelphia/ Adelaide: Multilingual Matters LTD.

Baker, M. (1995). Corpora in translation studies. An overview and suggestion for future research. Target 7(2): 223-245.

Baker, M. (2001). Routledge encyclopaedia of translation studies. New York: Routledge

Buhalis, D. (2003). eTourism: Information technology for strategic tourism management: Prentice Hall.

Chesterman, Andrew. 1993. From "is" to "ought": Laws, norms and strategies in translation studies. Target 5(1): 1-20.

Chiaro, D. (2008). Issues of quality in screen translation: Problems and solutions. In: D. Chiaro, C. Heiss, \& C. Bucaria (Eds.), Between text and image updating: Research in screen translation (pp. 241-257). Amsterdam/ Philadelphia: John Benjamins. 


\section{Sina Shams \& Reza Gholami}

Cyr, D., \& Trevor-Smith, H. (2004). Localization of Web Design: An Empirical Comparison of German, Japanese, and U.S. Website Characteristics. American Society for Information Science and Technology, 55(13), 1-10.

Denzin, N. K., \& Lincoln, Y. S. (Eds.). (2011). The Sage handbook of qualitative research. Sage.

De Troyer, O., \& Casteleyn, S. (2004). Designing Localized Web Sites. 5th International Conference on Web Information Systems Engineering (WISE2004) (pp. 547-558). Brussel: Springer.

Diaz-Citas, J. (2008). Audiovisual translation comes of age. In D. Chiaro, C. Heiss, \& C. Bucaria (Eds.), Between text and image updating: Research in screen translation (pp.111). Amsterdam/ Philadelphia: John Benjamins.

Fernando, I.N., Long, W. (2012), „New conceptual model on cluster competitiveness: A new paradigm for tourism?", International Journal of Business and Management, (7) 9, pp. 75-84.

Fominiene, V. B. (2016). The Importance of Tourism Websites to Tourism Services And Assurance Of Their Competitiveness. Montenegrin Journal of Economics, 12(4), 41.

Freshwater, H. (2004). Towards a redefinition of censorship. In: Diaz_Diocaratz, M. (eds), Critical studies (pp. 225-245). Amsterdam and New York: Rodopi.

Holmes, J. S. (1988). The name and nature of translation studies, in L. Venuti (Ed.) (2000)

Ivacovoni, A. (2009). Translation by Omission. Retrieved from: http:/ /iacovoni. wordpress.com /2009/02/01/translation-by-omission/

Karamitroglou, F. (2001). The choice between subtitling and revoicing in Greece. In Target, $15(2), 305-315$.

Kauhanen, I. (2010). Norms and sociolinguistic description. Retrieved: October 22, 2010,from: http://www.ling.helsinki.fi/sky/julkaisut/SKY20 06_1/1FK60.1. 4.KAUHANEN. pdf

Law, R., Buhalis, D., \& Cobanoglu, C. (2014). Progress on information and communication technologies in hospitality and tourism. Information and communication technologies in hospitality and tourism, 727-750.

Law, R., Qi, S., \& Buhalis, D. (2009). Progress in tourism management: A review of website evaluation in tourism research. Tourism Management, 31, 297-313.

Leppihalme, R. (1997). Culture bumps: An empirical approach to the translation of allusions. Philadelphia: Multilingual Matters.

Lommel, A., \& Ray, R. (2007). The Globalization Industry Primer. An introduction to preparing your business and products for success in international markets. Switzerland: The Localisation Industry Standards Association.

Lončarić, D., Bašan, L., \& Marković, M. G. (2013). Importance of DMO websites in tourist destination selection. In 23rd CROMAR Congress: Marketing in a Dynamic åEnvironment-Academic and Practical Insights, 373-386.

Mele, E., De Ascaniis, S., \& Cantoni, L. (2015). Localization of National Tourism Organizations' websites: How are World Heritage Sites portrayed online by European destinations for different markets. In Heritage, Tourism \& 
Morrison, A. M., Taylor, J. S., \& Douglas, A. (2004). Web site evaluation in hospitality and tourism: The art is not yet stated. Journal of Travel \& Tourism Marketing, 17(2/3), 233251.

Munday, J. (2001). Introducing translation studies: Theories and applications. London and New York: Routledge.

Nauert, S. (2007). Translating websites. Proceedings of the Marie Curie Euroconferences MuTra: LSP translation Scenarios-Vienna, 30, 1-10.

Nouraey, P., \& Karimnia, A. (2012). A meta-look at current translation studies trends in Iran: Insights from translation studies MA theses. British Journal of Social Sciences, 1(1), 94-116.

Safaei, F., \& Vahid Dastjerdi, H. (2017). A Stylistic Approach to Translation: Figurative language devices in the Persian renderings of Alcott's Little Women. International Journal of Foreign Language Teaching and Research, 5(19), 37-50.

Schaffner, Ch. (1999). The concept of norms in translation studis. In C. Schaffner (Ed.),

Sedighi, A., \& Najian, T. S. (2012). On audiovisual translation: The effect of norms of dubbing 1 taboos into Persian movies after the Islamic revolution in Iran. Journal of Language and translation, 3(1), 37-49.

Singh, N., Furrer, O., \& Ostinelli, M. (2004). To Localize or to Standardize on the Web: Empirical Evidence from Italy, India, Netherlands, Spain, and Switzerland. The Multinational Business Review , 69-87.

Somers, Harold (ed.) (2003). Computers and Translation: A Translator's guide. Amsterdam - Philadelphia: John Benjamins.

Tigre Moura, F., Gnoth, J., \& Deans, K. R. (2014). Localizing Cultural Values on Tourism Destination Websites: The Effects on Users' Willingness to Travel and Destination Image. Journal of Travel Research , 1-15.

Toury, Gideon (1995), Descriptive Translation Studies and beyond (Amsterdam, Philadelphia: Benjamins).

Venuti, L. (Ed.). (2012). The translation studies reader. Routledge.

Vossoughi, H., \& Etemad, H. Z. (2013). Norms of translating taboo words and concepts from English into Persian after the Islamic revolution in Iran. Journal of language and translation, 3, 2(5), 1-6.

Wang, Y. (2008). Examining the level of sophistication and success of destination marketing systems: Impacts of organizational factors. Journal of Travel \& Tourism Marketing, 24(1), 81-98.

Wardhaugh, R. (1990). An introduction to sociolinguistics. Oxford: Basil Blackwel

Williams, J., \& Chesterman, A. (2002). The map: A beginner's guide to doing research in translation studies. Manchester, U.K.: St. Jerome Pub.

Yuan, Y. L., Gretzel, U., \& Fesenmaier, D. R. (2006). The role of information technology use in American convention and visitors bureaus. Tourism Management, 27(2), 326-341. 